\title{
Sharing leadership: current attitudes, barriers and needs of clinical and non-clinical managers in UK's integrated care system
}

\author{
Lisa Aufegger $\odot{ }^{1,2}$ Monica Alabi, ${ }^{2}$ Ara Darzi, ${ }^{1,2}$ Colin Bicknell ${ }^{1,2}$
}

- Additional material is published online only. To view please visit the journal online (http://dx.doi.org/10.1136/ leader-2020-000228).

${ }^{1}$ Patient Safety Translational Research Centre, Imperial College London, London, UK ${ }^{2}$ Centre for Health Policy, Imperial College London, London, UK

\section{Correspondence to}

Dr Lisa Aufegger, NIHR Imperial Patient Safety Translational Research Centre, London, Imperial College London, London W2 1PE, UK; l.aufegger@imperial.ac.uk

Received 25 February 2020 Revised 25 April 2020

Accepted 28 April 2020 Published Online First 13 May 2020

\begin{abstract}
Background As systems become more complex, shared leadership (SL) has been suggested to have a dominant role in improving cross-functional working tailored to organisational needs. Little, however, is known about the benefits of SL in healthcare management, especially for UK's recently formed integrated care system (ICS). The aim of this study was to understand current attitudes, barriers and needs of clinical and non-clinical managers sharing leadership responsibilities in the ICS.
\end{abstract}

Method Twenty clinical and non-clinical leaders in 15 organisations were interviewed to understand current cross-functional leadership collaborations, and the potential SL may have on the recently established ICS in the National Health Service (NHS). The data were transcribed and analysed thematically.

Results Findings showed perceptions and experiences of clinical and non-clinical healthcare management in relation to: (1) motivation to execute a leadership position, including the need to step up and a sense of duty; (2) attitudes towards interdisciplinary working, which is reflected in conflicts due to different values and expertise; (3) SL skills and behaviours, including the need for mutual understanding and cooperative attitudes by means of effective communication and collaboration; and (4) barriers to achieve SL in the ICS, such as bureaucracy, and a lack of time and support.

Conclusions SL may help improve current leadership cultures within the NHS; however, for SL to have a tangible impact, it needs to be delivered as part of leadership development for doctors in postgraduate training, and development programmes for aspiring, emerging and established leaders, with clear lines of communication.

\section{INTRODUCTION}

Leadership has been suggested as one of the most influential factors in shaping organisational culture, ${ }^{12}$ with effective leadership being associated with fundamental health services improvements, including greater staff well-being, decreased turnover rates and an overall increase in quality of care. ${ }^{3-5}$ However, while leadership is influential, the type of leadership is even more so. ${ }^{6-8}$ A number of different leadership models exist; while some focus on a single leader, others adopt a more shared approach, emerged in response to the demands created by increasing complexity, change and multidisciplinary nature of work and collaborations. ${ }^{9-11}$

Shared leadership (SL) has been recognised as a meaningful tool to improve cross-functional working. ${ }^{12} \mathrm{SL}$ implies mutual influence and shared responsibility among team members, whereby members lead one another towards achieving a group or organisational goal or both. ${ }^{13}$ It fosters both task-related and social dimensions of group functioning, such as by having a shared purpose and social support, which, in turn, enhances productivity and organisational performance. ${ }^{14}$ SL is not static and leadership roles can be assumed by different team members either at the same time or at various points during the team's life-cycle. ${ }^{15}$ As such, team and contextual dynamics allow for emergences of leaders, and the conditions that influence how SL can evolve over time. ${ }^{1617}$

When SL is executed, team members are believed to bring more resources to the task, share more information and experience higher commitment with the team, ${ }^{18}$ generating greater levels of trust and respect. ${ }^{19}$ This appears a valuable asset especially in managing health service and care, where multidisciplinary teams consisting of both clinical and non-clinical managers frequently experience tension due to divergent skills and ways of thinking, as well as the isolated nature of how each often chooses to operate vis-à-vis the other. ${ }^{20}$

\section{Context}

In 2016, forty-four sustainability and transformation partnerships covering the whole of England were formed, including multispecialty community providers, such as primary and acute care systems, urgent and emergency care networks, and maternity services. These sustainability and transformation partnerships comprised National Health Service (NHS) trusts, local authorities and clinical commissioning groups. For each area in England, a multidisciplinary team was appointed to be responsible for the implementation of agreed population plans, which, in February 2018, became known as integrated care systems (ICS). By 2021, ICS in England will be a mandatory and integrated part of the NHS, responsible for managing resources, delivering NHS standards and improving the health of the population it serves. ${ }^{21}$ In doing so, ICS relies on clinicians and managers working closely together, to help foster cross-organisational working and provide care tailored to individual needs. ${ }^{22}$

\section{Aim}

Successfully sharing leadership will rely on clinicians and managers working closely together to deliver high quality of care. Previous evidence suggests that a productive relationship between managers and clinicians is correlated with better patient
To cite: Aufegger $\mathrm{L}$, Alabi $\mathrm{M}$ 2020:4:128-134. 
outcomes. ${ }^{2324}$ As the ICS is still developing, this study sets out to understand the current culture of collaboration between clinical and non-clinical healthcare managers, and to explore perceived barriers and benefits of SL in the NHS. Specifically, we wish to understand current attitudes, barriers and needs of clinical and non-clinical managers in UK's ICS, and explore perceptions of SL skills and behaviours necessary to achieve success in their provision of healthcare service and delivery.

\section{METHODS}

\section{Sample}

Participants were recruited as part of purposive sampling, via the ICS management office. Information about the study, the purpose and why they had been invited to participate were provided. Written consent was obtained prior to interviews. Inclusion criteria were that participants had to be either a clinical or a non-clinical manager with leadership responsibilities for at least 5 years, and that are part of and work within the ICS.

Twenty participants were interviewed (age range: 35-50 years); 10 with a clinical background, including 9 general practitioners and 1 nurse, and 10 with a non-clinical background. All of them worked in senior leadership positions in the ICS.

\section{Interview}

Audio-recorded, semistructured interviews were conducted that addressed (non-)clinical managers' (A) experience in leadership positions, (B) their attitude towards SL in ICS, (C) barriers and enablers of working with (non-)clinical managers, and (D) the skills and behaviours they believe valuable for achieving SL in the ICS (cf Questionnaire in online supplementary material).

\section{DATA PROCESSING AND ANALYSIS}

The audio recordings were transcribed by an external company for an agreed fee. A qualitative approach using thematic analysis was used to interpret the results. Thematic analysis allows for identifying, analysing and reporting patterns or themes within data from an inductive, semantic, iterative approach. ${ }^{25} 26$ This included reading the data several times in order to get familiar with the depth and breadth of the content, which is the 'a key phase of data analysis within interpretative qualitative methodology'. ${ }^{27}$ Next, a set of initial lists of ideas from the data were generated, expressed in codes from the data that appeared meaningful to the first and second authors. With a clear sense of context, the coding process enabled to organise the data into meaningful groups, before being grouped into broader, overarching themes. Embedded into an initial thematic map, and after further evaluation and refinement of the themes, the authors aimed for a coherent pattern which considers the validity of the individual themes, as well as whether the thematic map accurately reflects the meanings evident in the whole data set. Finally, the collated data were organised into an internally consistent account with accompanying narrative and supported by quotes from participants that capture the essence of the point being demonstrated. The analytical narrative was done in consideration of perceptions and attitudes towards SL in the ICS.

\section{RESULTS}

Findings from the thematic analysis revealed four main themes, including: (1) motivation to execute a leadership position; (2) attitudes towards interdisciplinary working; (3) SL skills and behaviours; and (4) barriers to achieve SL in the ICS. Similarities and discrepancies of both groups are highlighted below (cf figure 1 for an overview of each theme and example quotes).

\section{Motivation to execute a leadership position}

Leadership motivation is expressed in participants' ability to identify what inspired them to take on strategic leadership, and that '....affects a leader's or leader-to-be's decisions to assume leadership training, roles and responsibilities'. ${ }^{28}$ Findings from this study suggested that both non-clinical and clinical managers did not set leadership as a career goal, with clinical managers feeling a sense of 'discomfort', reflected in an identity conflict triggered by a dual role responsibly of treating patients while also managing care. Non-clinical managers' decision to take on a leadership role was reflected in a sense of duty towards team members and a dedication to the organisational goals within the context of the national mandate. In contrast to clinical managers, they showed a greater level of embracement towards the opportunities that were presented (cf table 1).

\section{Attitudes towards interdisciplinary working}

Shared commitment in leadership and from healthcare and managerial professions is needed to create effective healthcare service and delivery. Historically, however, both have struggled working together, due to different work ethic, dissimilar styles of solving problems or even contrasting values. ${ }^{29} 30$ The findings from this study suggest that tensions exist, reflected in conflicts due to different values and expertise (cf table 2).

\section{SL skills and behaviours}

SL skills and behaviours were emphasised in terms of (1) mutual understanding and cooperative attitudes; (2) listening, empathy and emotional intelligence; and (3) effective communication and collaboration to enable knowledge transfer and translation. To illustrate, both groups expressed the wish to share a common vision and to have a mutual understanding of the NHS processes and its importance in relationship to improving healthcare. Specifically, suggestions were made in relation to clear inductions for clinicians taking on leadership roles, frequent collaboration with non-clinical managers, as well as early communication to avoid misunderstanding, solve problems and diffuse conflicts. By openly asking for advice and eliciting the right information, they recognised that responses are encouraged, relationships are created and a cooperative attitude established. Lastly, the importance of listening, empathy and emotional intelligence (ie, ability to manage one's own and others' emotions) was highlighted as assets of SL, increasing understanding of each other's roles and responsibilities, and to allow for knowledge transfer and translation into actionable messages (cf table 3).

\section{Barriers to achieve SL in the ICS}

SL is dynamic and involves interacting with others within the group. It is manifested by behaviours such as communicating, influencing, making suggestions and holding members accountable. ${ }^{31}$ Barriers were evident in both groups and deeply entrenched and similar in terms of views of the other. In particular, frustration was expressed in association with bureaucracy, lack of role and goal clarity, and time pressures, especially when holding dual roles (cf table 4).

\section{DISCUSSION}

\section{Summary of findings}

Literature proposes benefits of SL for healthcare systems, which enables the combination of expertise and resources to bring change, improvement in service outcomes and enhancement in organisational capability. ${ }^{12} 3233$ 


\begin{tabular}{|c|c|c|}
\hline Main themes & Non-clinical managers & Clinical managers \\
\hline $\begin{array}{l}\text { Motivation to execute a } \\
\text { leadership position }\end{array}$ & $\begin{array}{l}\text { "It was probably more of a } \\
\text { calling than an ambition to go } \\
\text { into leadership. I just } \\
\text { probably fell naturally into it." }\end{array}$ & $\begin{array}{c}\text { "I always saw myself as } \\
\text { a clinician and not a } \\
\text { leader in that sense." }\end{array}$ \\
\hline $\begin{array}{l}\text { Attitudes towards } \\
\text { interdisciplinary working }\end{array}$ & $\begin{array}{c}\text { "The majority [of clinical } \\
\text { managers] want to do a good } \\
\text { job but they are not looking } \\
\text { at the bigger picture." }\end{array}$ & $\begin{array}{l}\text { "The big issue is always we } \\
\text { speak a different language. It's a } \\
\text { totally different outlook on the } \\
\text { world if you're a doctor and you } \\
\text { think in single-patient terms." }\end{array}$ \\
\hline $\begin{array}{c}\text { Shared leadership skills and } \\
\text { behaviours }\end{array}$ & $\begin{array}{l}\text { "Having a common strategic } \\
\text { vision and engaging in processes } \\
\text { that organisations have put in } \\
\text { place in order to get towards } \\
\text { this common vision." }\end{array}$ & $\begin{array}{l}\text { "More inclusion. Keep them } \\
\text { informed, ask their opinion } \\
\text { and don't impose things on } \\
\text { them because then there'll be } \\
\text { resistance." }\end{array}$ \\
\hline $\begin{array}{c}\text { Barriers to execute shared } \\
\text { leadership in the ICS }\end{array}$ & $\begin{array}{c}\text { "[There is a] resistance } \\
\text { to letting go of the } \\
\text { ways that they have } \\
\text { always worked." }\end{array}$ & $\begin{array}{l}\text { "Organisational barriers, } \\
\text { the context we're working } \\
\text { in, the actual structure, } \\
\text { governance setup." }\end{array}$ \\
\hline
\end{tabular}

Figure 1 Overview of themes with example quotes. ICS, integrated care system.

This study set out to understand the current culture of collaboration between clinical and non-clinical healthcare managers, and to explore perceived barriers and benefits of SL in the NHS. Findings from semistructured interviews and thematic analyses revealed four emerging themes: (1) motivation to execute a leadership position; (2) attitudes towards interdisciplinary working; (3) SL skills and behaviours; and (4) barriers to achieve SL in the ICS.

The majority of the clinical managers showed a low motivation to lead, which was shaped by a lack of support and the

Table 1 Quotes addressing the theme 'Motivation to execute a leadership position'

\begin{tabular}{|c|c|}
\hline Non-clinical managers & Clinical managers \\
\hline $\begin{array}{l}\text { 'It was probably more of a calling than an } \\
\text { ambition to go into leadership. I just probably } \\
\text { fell naturally into it.' }\end{array}$ & $\begin{array}{l}\text { 'I always saw myself as a clinician and } \\
\text { not a leader in that sense.' }\end{array}$ \\
\hline $\begin{array}{l}\text { 'I don't think it was ever a conscious choice, you } \\
\text { fall into roles but actually with management } \\
\text { there comes a responsibility to lead. You have } \\
\text { got people there that you're responsible for and } \\
\text { it's important that they see some direction.' }\end{array}$ & $\begin{array}{l}\text { 'I happened to be the oldest person } \\
\text { there, and not based on the grounds } \\
\text { of any degree of ability, I was given a } \\
\text { leadership role whether I wanted to do } \\
\text { it or not.' }\end{array}$ \\
\hline $\begin{array}{l}\text { 'I have always wanted to make things better, } \\
\text { improve things... and I have made a career } \\
\text { out of it.' }\end{array}$ & $\begin{array}{l}\text { 'They needed a director, everyone ran } \\
\text { and I was left standing there.' }\end{array}$ \\
\hline
\end{tabular}

creation of a mixed leadership identity, which was in conflict with clinicians' daily workflow activities. In contrast, nonclinical managers projected a sense of duty about their leadership positions and welcomed the change as part of their natural career progression.

SL requires high levels of dialogue and debate. ${ }^{13} 34$ Therefore, leaders must pursue effective collaboration strategies. ${ }^{35}$

Table 2 Quotes addressing the theme 'Attitudes towards interdisciplinary working'

\begin{tabular}{ll}
\hline Non-clinical managers & Clinical managers \\
\hline $\begin{array}{l}\text { 'The general problem we have with clinicians } \\
\text { is that medical training teaches to do the }\end{array}$ & $\begin{array}{l}\text { At the moment, it's them and us and it } \\
\text { best for the patient in front of you and not } \\
\text { about the bigger picture.' } \\
\text { clinicians are an important part of the } \\
\text { structure.' }\end{array}$ \\
$\begin{array}{ll}\text { 'The majority [of clinical managers] want to } \\
\text { do a good job but they are not looking at the }\end{array}$ & $\begin{array}{l}\text { 'I think it takes practice and patience. It } \\
\text { does take a while to get the trust of non- } \\
\text { bigger picture.' }\end{array}$ \\
$\begin{array}{ll}\text { clinicians. What they want in a clinical } \\
\text { leader is somebody to front up things, which } \\
\text { is usually bad!' }\end{array}$ \\
$\begin{array}{ll}\text { 'I find it really important both to engage } \\
\text { and work with clinical colleagues, but [...] } \\
\text { you need to understand both the patient's } \\
\text { perspective and the impact on clinical } \\
\text { practice.' }\end{array}$ & $\begin{array}{l}\text { language. It's a totally different outlook on } \\
\text { the world if you're a doctor and you think in } \\
\text { single-patient terms.' }\end{array}$ \\
\hline
\end{tabular}

Aufegger L, et al. BMJ Leader 2020;4:128-134. doi:10.1136/leader-2020-000228 
Table 3 Subthemes and quotes addressing the theme 'Shared leadership skills and behaviours'

\begin{tabular}{|c|c|c|}
\hline Subtheme & Non-clinical managers & Clinical managers \\
\hline \multirow[t]{2}{*}{$\begin{array}{l}\text { Mutual understanding and } \\
\text { cooperative attitudes }\end{array}$} & $\begin{array}{l}\text { 'You have got to find some commonality. Make sure you collaborate, } \\
\text { don't be positional, so don't assume that just because you're a GP- } \\
\text { which comes with a level of kudos, comes with a level of authority } \\
\text { and power-just because of your title, don't assume that people will } \\
\text { do things because of that.' }\end{array}$ & $\begin{array}{l}\text { 'They need to understand where the clinician is coming from. For us, it is } \\
\text { about the patient and if we keep our patients happy, then our lives will be } \\
\text { less difficult as clinicians.' }\end{array}$ \\
\hline & $\begin{array}{l}\text { 'Having a common strategic vision and engaging in processes that } \\
\text { organisations have put in place in order to get towards this common } \\
\text { vision.' }\end{array}$ & $\begin{array}{l}\text { 'They have got to be able to look at how to communicate intentions in } \\
\text { terms of how that improves patient experience, how that improves clinical } \\
\text { outcomes and how that improves the day-to-day life of clinicians and non- } \\
\text { clinicians on the frontline.' }\end{array}$ \\
\hline \multirow[t]{2}{*}{$\begin{array}{l}\text { Listening, empathy and } \\
\text { emotional intelligence }\end{array}$} & $\begin{array}{l}\text { 'There is something around being able to listen, being able to build } \\
\text { relationships and being able to look at how you do things in a } \\
\text { collaborative way.' }\end{array}$ & 'Articulating the problem in a way that people can understand it.' \\
\hline & $\begin{array}{l}\text { 'The buzzword is emotional intelligence; [to] read situations well and } \\
\text { adapt to them.' }\end{array}$ & $\begin{array}{l}\text { 'More inclusion. Keep them informed, ask their opinion and don't impose } \\
\text { things on them because then there'll be resistance.' }\end{array}$ \\
\hline \multirow{2}{*}{$\begin{array}{l}\text { Effective communication } \\
\text { and collaboration to enable } \\
\text { knowledge transfer and } \\
\text { translation }\end{array}$} & $\begin{array}{l}\text { 'I spent a lot of time going around practices with the medical } \\
\text { director and it instilled in me an understanding of clinicians.' }\end{array}$ & 'I have learnt that having a clinical perspective alone doesn't work.' \\
\hline & $\begin{array}{l}\text { 'I think you learn something every day from clinicians. I have } \\
\text { worked in various organisations but I'm not sure I have ever really } \\
\text { understood primary care.' }\end{array}$ & $\begin{array}{l}\text { 'I have definitely picked up a far better understanding of the financial } \\
\text { decision-making going on in the NHS. I have developed a keen } \\
\text { understanding of just how much, at the high level, managers are } \\
\text { responsible to politicians. I have got far more knowledge around } \\
\text { population health.' }\end{array}$ \\
\hline
\end{tabular}

GP, general practitioner; NHS, National Health Service.

Clinical managers expressed concerns that managers underestimated the time constraints they were under or the difficulty in executing managerial leadership while also pursuing clinical responsibilities. Non-clinical managers also highlighted a need for clinical managers to engage themselves more around systems and processes, instead of focusing on a single-patient view only. These findings are in line with the concept of clinicians who form a hybrid manager-professionals' identity, ${ }^{36}$ who either embrace their managerial role as part of formative identity work or who are protective of traditional professionalism and only temporary engaging in managerial roles. In this study, clinicians are yet to fully embrace managerial responsibilities, due to the lack of perceived support and time.

Identified important SL skills and behaviours for a successful ICS were (1) a mutual understanding and cooperative attitudes; (2) listening, empathy and emotional intelligence; and (3) effective communication and collaboration to enable knowledge transfer and translation. It was perceived important that (non-)

Table 4 Quotes addressing the theme 'Barriers to achieve shared leadership in the ICS'

\begin{tabular}{|c|c|}
\hline Non-clinical managers & Clinical managers \\
\hline $\begin{array}{l}\text { 'Sometimes, clinicians can become very } \\
\text { entrenched in their own view and their } \\
\text { own way, and that is the only way.' }\end{array}$ & $\begin{array}{l}\text { 'Lack of clarity of goals and when your } \\
\text { goals don't align with our [own] goals. I } \\
\text { don't blame them, we're not part of the } \\
\text { same organisation, they're jumping to a } \\
\text { slightly different tune to us.' }\end{array}$ \\
\hline $\begin{array}{l}\text { 'Clinicians work under extreme } \\
\text { constraints of time; and sometimes as } \\
\text { managers, we do have the luxury of } \\
\text { having a meeting, and mulling things } \\
\text { over.' }\end{array}$ & $\begin{array}{l}\text { 'Our time is just so pulled across in so many } \\
\text { places. There is always going to be conflict } \\
\text { when you have got essentially a part-time } \\
\text { contributor and a full-time team member.' }\end{array}$ \\
\hline $\begin{array}{l}\text { '[There is a] resistance to letting go } \\
\text { of the ways that they have always } \\
\text { worked.' }\end{array}$ & $\begin{array}{l}\text { 'Organisational barriers, the context we're } \\
\text { working in, the actual structure, governance } \\
\text { setup.' }\end{array}$ \\
\hline
\end{tabular}

ICS, integrated care system. clinical managers acknowledge each other's points of view and empathise and give credits to each other's expertise, while effective communication and collaboration were emphasised crucial to allow for each entity to become more fluid, flexible and adaptable. It was also highlighted that a lack in managerial expertise and clinical experience, respectively, should be tackled by generating a greater awareness of the context of the work they both do, in order to allow for knowledge transfer and translation to lead into actionable messages.

Lastly, findings demonstrated some tensions and barriers for successfully engaging in SL in the ICS. Clinical managers felt a sense of isolation as they straddle both clinical and non-clinical commitments. In contrast, managers expressed a need for clinical leaders to acquire knowledge around systems and processes, and embraced a shared vision by bridging the gap between clinical care and managing the wider healthcare system. These findings are in alignment with other studies, ${ }^{37}$ demonstrating that a negative attitude towards the medical leadership agenda, negative senior role modelling and lack of real-world corporate experience are real barriers for successful healthcare leadership of clinicians. ${ }^{37}$

\section{General discussion}

Clinicians working in the ICS often are considered as being outside the core leadership team, as they usually have dual roles, with their clinical role taking precedence. Being part of the team is important to SL, as the influence of leaders within a group is based on a sense of psychological connection or identification with the wider organisation, the particular group and its leadership. ${ }^{38}$ When there is a sense of shared social identity, intrinsic motivation results, leading to behaviour in line with the organisational goals and objectives. ${ }^{39}$ The role of the social identity process of being part of a team, should, ideally, be established early on.

SL is generally assumed to be internal and informal, ${ }^{40}$ which emerges through a complex process of role taking and peer 
perception. ${ }^{41}$ Political skills, within the broader context of social networks, will play a role in the development of SL, ${ }^{42}$ because it enables individuals more accurately to comprehend the needs of organisations and their members, and help others map the informal communication pathways embedded within these organisations. ${ }^{43}$ Because of this, it is necessary to recognise informal leaders; identify their distinct characteristics; and understand how they can support organisational effectiveness through their performance as part of the team. ${ }^{44}$

Lastly, SL acknowledges the involvement of multiple roles and functions that leaders may have in their positions. This allows for a mechanism where leadership responsibilities can be distributed among team members to facilitate completion. ${ }^{45}$ The work of the ICS is complex, highly knowledge based and requires a large degree of information sharing and interdependent activities between team members. ${ }^{18}$ Collective engagement in leadership by multiple individuals through both formal and informal relationships will enable a capability for facing increasingly complex workplace, business and social challenges. ${ }^{46}$

\section{Implications for practice and research}

Findings of this study emphasise the importance of SL, which relies on individuals influencing and leading one another to achieve organisational goals. Similar to other studies, ${ }^{12}$ participants emphasised that interaction and engagement have to be bilateral, ${ }^{47}$ and require high levels of dialogue, debate and discussion to achieve a shared understanding of problems and solutions. ${ }^{48}$

One important enabler of change will be continuous education and training. ${ }^{49}$ Both clinical and non-clinical managers will play a critical role in shaping and supporting their ICS. ${ }^{50}$ For this to happen, they must be supported towards an SL that creates compassionate and inclusive cultures and that inspires commitment to create healthy communities and service users. Guidance should be drawn from the wealth of research in clinical leadership development, which refers to '...a physician's ability to serve as both a manager and a leader of diverse teams in pursuit of maximally effective patient care'. ${ }^{51}$ Clinical leadership training can include aspects on system thinking, communication influence, results orientation and cultural competencies. ${ }^{51}$ For SL in the ICS, these, alongside a focus on the development of a better role identity, which is associated with believing in certain values, standards and expectations, should be encouraged. ${ }^{52}$ For clinical managers, the coexistence of clinical and managerial tasks is likely to jeopardise the ability to execute their leadership roles with efficacy, which, in turn, affects their motivation to lead. Role identity needs to be aligned with their established professional identity developed over years, and include a focus on the leader as a person, not just the role. ${ }^{53}$

The pace of progress and quality in developing SL in healthcare institution will depend on how these resources are valued and distributed. ${ }^{54}$ Managers and clinicians alike will be an important factor in supporting the diffusion and adaption of SL, reflected in finding a common ground to create credibility and trust, an increased effort in engaging peers, and by efficiently influencing resources, and enacting on hybrid leadership responsibilities. ${ }^{54}$ Only by collectively fostering a shift from individualistic, hierarchical leadership, working primarily within and for a single team, and hindering a natural career progression into management and leadership roles, ${ }^{37}$ to an SL that creates compassionate and inclusive cultures, can we inspire commitment and largescale change. ${ }^{49}$
Lastly, leadership development programmes will need to include 'learn while doing' approaches, combine learning from evidence, personal experience, and a focus on the leader as a person, not just the role. This should be provided by means of horizontal as well as vertical development alongside the application of innovative methods such as paired learning, role modelling and simulation training. ${ }^{55}$ Paired learning is a peer-learning tool that links together different professional groups to develop a shared attitude and decision-making in order to create a common ground for values in their work domain. Paired learning programmes have been trialled in various organisations and have shown an increase in preparedness for working in partnership and a better understanding of structures and hierarchies. ${ }^{56}$ Role modelling enables clinical and non-clinical managers to observe and learn skills and competencies related to healthcare and management, and, alongside simulation training, enables both groups to experiment on executing SL skills and behaviours without fear, to reflect on the process of team and task work and to view errors as learning and improvement opportunity. ${ }^{57}$

From a research perspective, future studies should address SL in the wider team contexts, such as in smaller teams across the area could be carried out. It is also recommended to design and evaluate implemented SL learning based on predetermined SL skills and behaviours as measures of quality and success, and to assess discrepancies between indented and observed outcomes at an individual, team and systemic level. Lastly, virtually no evidence exists on the sustainability of shifts towards SL in healthcare management; thus, future studies should pay attention to contextual dynamics that allow for emergence of leaders, and the conditions that influence how SL can evolve over time. ${ }^{17}$

\section{Strengths and limitations}

This research provides a unique insight into the current state of leadership among clinical and non-clinical managers and the potential benefits of SL between these two groups in the ICS.

The participants were selected from a range of organisations and roles were varied, allowing for a wide examination and more diverse data. In particular, general practitioners have a different experience of leadership development, and practice is different from doctors in other contexts. Similarly, nurses undergo a different preparation for and experience of leadership. ${ }^{58}$ Thus, the degree of translating these findings to other settings is limited.

A limitation of this study is that the interviewer worked in ICS, which may have biased the data analysis process. However, because the data were explored and evaluated by two independently working reviewers, potential biases in data processing and interpretations were reduced to a minimum.

\section{Recommendations to train and improve SL in the ICS}

From this research, themes were derived that provide areas for recommendations to improve SL in the ICS.

Recommendations include but are not limited to:

- Introducing and training of SL competencies into the curricula of both clinical and non-clinical managers, reinforced through (A) paired learning, (B) role modelling, and (C) simulation training.

- Adapting clinicians' time management regimes to allow for an efficient role execution.

- Establishing organisational change that creates a culture built on well-defined roles, expertise, credibility and SL.

\section{CONCLUSION}

Good leadership can have a great impact on the quality of an organisational culture. This research was undertaken to examine 
the role of clinicians and managers in sharing leadership in the ICS. Findings suggest that SL may be a meaningful tool to provide an opportunity for both groups to use their expertise, and to jointly shape and lead the system. However, this can only be achieved by active steps towards more effective interactions, including a supportive environment that maintains high standards of practice while also enabling to use resources wisely. Future development programmes are encouraged to incorporate this vision.

Acknowledgements We thank the National Institute for Health Research (NIHR) Imperial Patient Safety Translation Research Centre (PSTRC) for its support of this research. We also thank all participants for their contribution to and participation in this study.

Contributors $L A, M A, C B$ and $A D$ conceptualised this research. $L A$ and $M A$ designed the protocol and $C B$ and $A D$ contributed to the conceptualisation and commented on the protocol. The data collection and analysis were carried out by MA and LA. The manuscript was written by LA with contributions from all authors. All authors have read and approved the manuscript.

Funding This article represents independent research supported by the NIHR Imperial Patient Safety Translational Research Centre.

Disclaimer The views expressed are those of the author(s) and not necessarily those of the NHS, the NIHR or the Department of Health and Care. The funder had no role in study design, data collection and analysis, decision to publish or preparation of the manuscript.

Competing interests None declared.

Patient consent for publication Not required.

Ethics approval The study was reviewed and ethically approved by the Joint Research Compliance Office (JRCO; 18IC4917), Imperial College London, UK.

Provenance and peer review Not commissioned; externally peer reviewed.

Data availability statement No data are available. The data are not available for third entities due to ethical regulations on data collection, analysis and distribution.

\section{ORCID iD}

Lisa Aufegger http://orcid.org/0000-0003-2332-8677

\section{REFERENCES}

1 Barnett RC, Weidenfeller NK. Shared leadership and team performance. Advances in Developing Human Resources 2016.

2 Yukl G. Leadership in organizations. 6th edn. Upper Saddle River, NJ: Pearson Education, 2006

3 Forsyth C, Mason B. Shared leadership and group identification in healthcare: the leadership beliefs of clinicians working in interprofessional teams. J Interprof Care 2017;31:291-9.

4 Günzel-Jensen F, Jain AK, Kjeldsen AM. Distributed leadership in health care: the role of formal leadership styles and organizational efficacy. Leadership 2016;14:110-33.

5 Han SJ, Lee Y, Beyerlein M, et al. Shared leadership in teams: the role of coordination, goal commitment, and knowledge sharing on perceived team performance. Team Performance Management: An International Journal 2017.

6 Hoch JE, Pearce CL, Welzel L. Is the most effective team leadership shared? Journal of Personnel Psychology 2010;9:105-16.

7 House RJ, Aditya RN. The social scientific study of leadership: quo vadis? Journal of Management 1997;23:409-73.

8 Yukl G, Van Fleet DD. Theory and research on leadership in organizations. In: Dunnette MD, Hough LM, eds. Handbook of industrial and organizational psychology. Palo Alto, CA: Consulting Psychologists Press, 1992: 147-97.

9 Warren OJ, Carnall R. Medical leadership: why it's important, what is required, and how we develop it. Postgrad Med J 2011;87:27-32.

10 DeNisi AS, Hitt MA, Jackson SE. The knowledge-based approach to sustainable competitive advantage. In: Jackson SE, DeNisi AS, Hitt MA, eds. Managing knowledge for sustained competitive advantage: designing strategies for effective human resource management. San Francisco: Jossey-Bass, 2003: 3-33.

11 Currie G, Lockett A. Distributing leadership in health and social care: Concertive, conjoint or collective? International Journal of Management Reviews 2011:13:286-300

12 Aufegger L, Shariq O, Bicknell C, et al. Can shared leadership enhance clinical team management? A systematic review. Leadersh Health Serv 2019;32:309-35.

13 Carson JB, Telsuk PE, Marrone JA. Shared leadership in teams: an investigation of antecedent conditions and performance. Academy of Management Journal 2007:50:1217-34
14 Wang D, Waldman DA, Zhang Z. A meta-analysis of shared leadership and team effectiveness. J Appl Psychol 2014;99:181-98.

15 Friedrich TL, Vessey WB, Schuelke MJ, et al. A framework for understanding collective leadership: the selective utilization of leader and team expertise within networks. The Leadership Quarterly 2009;20:933-58.

16 Mathieu JE, Kukenberger MR, D'Innocenzo L, et al. Modeling reciprocal team cohesion-performance relationships, as impacted by shared leadership and members' competence. J Appl Psychol 2015:100:713-35.

17 Kozlowski SWJ, Mak S, Chao GT. Team-Centric leadership: an integrative review. Annual Review of Organizational Psychology and Organizational Behavior 2016;3:21-54.

18 Ensley MD, Pearce CL. Shared cognition in top management teams: implications for new venture performance. Journal of Organizational Behavior 2001;22:145-60.

19 Day DV, Gronn P, Salas E. Leadership capacity in teams. The Leadership Quarterly 2004:15:857-80.

20 Hoff TJ. The social organization of Physician-Managers in a changing HMO. Work and Occupations 1999;26:324-51.

21 Maruthappu M, Sood HS, Keogh B. The NHS five year forward view: transforming care. Br J Gen Pract 2014:64:635-35.

22 Balkundi P, Ties HDA. leaders, and time in teams: Strong inference about network structure's effects on team viability and performance. Academy of Management Journal 2006:49:49-68.

23 Sarto F, Veronesi G. Clinical leadership and hospital performance: assessing the evidence base. BMC Health Serv Res 2016:16 Suppl 2:169.

24 Kirkpatrick I, Malby R, Dent M, et al. National inquiry into management and medicine: final report, centre for innovation in health management. University of Leeds, 2007.

25 Braun S, Peus C, Weisweiler S, et al. Transformational leadership, job satisfaction, and team performance: a multilevel mediation model of trust. The Leadership Quarterly 2013;24:270-83

26 Braun V, Clarke V. Using thematic analysis in psychology. Qualitative Research in Psychology 2006;3:77-101.

27 Bird CM. How I stopped Dreading and learned to love transcription. Qualitative Inquiry 2005;11:226-48.

28 Chan KY, Drasgow F. Toward a theory of individual differences and leadership: understanding the motivation to lead. J App/ Psychol 2001:86:481-98.

29 Lingard L, Vanstone M, Durrant M, et al. Conflicting messages: examining the dynamics of leadership on interprofessional teams. Acad Med 2012;87:1762-7.

30 Edwards N, Marshall M, McLellan A, et al. Doctors and managers: a problem without a solution? BMJ 2003:326:609.

31 Aime F, Humphrey S, DeRue DS, et al. The riddle of Heterarchy: power transitions in Cross-Functional teams. Academy of Management Journal 2013;57:327-52.

32 Chreim S, Williams BEB, Janz L, et al. Change agency in a primary health care context: the case of distributed leadership. Health Care Manage Rev 2010:35:187-99.

33 Boak G, leadership D. Team working and service improvement in healthcare. Leadership in Health Services 2015:28:332-44.

34 Simons T, Pelled LH, Smith KA. Making use of difference: diversity, debate, and decision comprehensiveness in top management teams. Academy of management journal 1999;42:662-73.

35 Wilson EJ, Sherrell DL. Source effects in communication and persuasion research: a meta-analysis of effect size. J Acad Mark Sci 1993;21:101-12.

36 McGivern G, Currie G, Ferlie E, et al. Hybrid manager-professionals' identity work: the maintenance and hybridization of medical professionalism in managerial contexts. Public Administration 2015;93:412-32.

37 Nicol ED, Cowpe J. Barriers to doctors successfully delivering leadership in the NHS. Future Hosp J 2016;3:21-6.

38 Lord RG, Brown DJ. Leadership, values, and subordinate self-concepts. The Leadership Quarterly 2001;12:133-52 https://doi.org/

39 Holyoak L. Psychology in organizations: the social identity approach. Leadership \& Organization Development Journal 2002;23:167-67.

40 Morgeson FP, DeRue DS, Karam EP. Leadership in teams: a functional approach to understanding leadership structures and processes. Journal of Management 2009;36:5-39

41 Neubert MJ, Taggar S. Pathways to informal leadership: the Moderating role of gender on the relationship of individual differences and team member network centrality to informal leadership emergence. Leadersh Q 2004:15:175-94.

42 Ammeter AP, Douglas C, Gardner WL, et al. Toward a political theory of leadership. Leadersh Q 2002:13:751-96.

43 Ferris GR, Treadway DC, Kolodinsky RW, et al. Development and validation of the political skill inventory. Journal of Management 2005:31:126-52.

44 Scott WG. Organization theory: an overview and an appraisal. J Acad Manag Ann 1961:4:7-26.

45 D'Innocenzo L, Mathieu JE, Kukenberger MR. A meta-analysis of different forms of shared leadership-team performance relations. Journal of Management 2014:20:1-28.

46 Cullen-Lester KL, Yammarino FJ. Collective and network approaches to leadership: special issue introduction. The Leadership Quarterly 2016;27:173-80 https://doi. org/ 


\section{Original research}

47 Shapiro J, Rashid S. Leadership in the NHS: professionals respond better to inclusion than to coercion. BMJ 2011;342:1271-2.

48 Limb M. Executives are "not in tune" with how doctors feel about NHS. BMJ 2014;348:g3461.

49 Swanwick T, Varnam R. Leadership development and primary care. BMJ Leader 2019;3:59.

50 Elliott C. Leadership without Bosses: shared leadership in the creation of a health network. Healthcare Management Forum 1994;7:38-43.

51 Blumenthal DM, Bernard K, Bohnen J, et al. Addressing the leadership gap in medicine: residents' need for systematic leadership development training. Academic Medicine 2012;87.

52 Hoque K, Davis S, Humphreys M. Freedom to do what you are told: senior management team autonomy in an NHS acute trust. Public Administration 2004;82:355-75.
53 DeRue DS, Ashford SJ. Who will lead and who will follow? A social process of leadership identity construction in organizations. Academy of Management Review 2010;35:627-47.

54 Wiedner R, Barrett M, Oborn E. The emergence of change in unexpected places: Resourcing across organizational practices in strategic change. Acad Manage J 2017:60:823-54.

55 Stumpf SA, Dunbar RLM. Using behavioral simulations in teaching strategic management processes. J Manag Educ 1990;14:43-62.

56 Houston JFB, Morgan JE. Paired learning - improving collaboration between clinicians and managers. J Health Organ Manag 2018;32:101-12.

57 de Zulueta PC. Developing compassionate leadership in health care: an integrative review. J Healthc Leadersh 2015;8:1-10.

58 Wylie DA, Gallagher HL. Transformational leadership behaviors in allied health professions. J Allied Health 2009;38:65-73. 